\title{
Power Grid Enterprises' Early-warning Operation System Modeling and Simulation Based on System Dynamics
}

\author{
Song Wei ${ }^{1 * \star}$, Liu Gang ${ }^{1}$, Zhang Luhua ${ }^{1}$ and Han Shuochen ${ }^{1}$ \\ ${ }^{1}$ State Grid Jibei Electric Power Company, Beijing, 100053
}

\begin{abstract}
As electricity system reform moved on, improving operation management level, operating risk pre-control is more and more important. To improve power grid enterprises' operating management level and business function performance, establishing an early-warning system in conformity with power grid enterprises' operation mode is necessary. Standing in the angle of the grid operation managers, this paper studies using system dynamics analyze power grid operation management level from business indicators interaction relationship to various business departments, and built power grid dynamic feedback relation model for early -warning of enterprise operation, and have an example analysis and the practical application, the result shows that the availability and applicability of the model.
\end{abstract}

\section{Introduction}

As electricity system reform moved on, improving operation management level, operating risk pre-control is more and more important. Currently, power grid enterprises have been fully carried out the construction of operation monitoring center ${ }^{[1-2]}$. To improve the business function performance of power grid enterprises and strengthen the "early-warning machine" effect of operation monitoring center, it is necessary to establish an early-warning system in conformity with the power grid enterprises' operation mode.

This paper will use system dynamics theory to construct the early warning operation model of power grid enterprises, and by means of one provincial power network enterprise's data from 2013 to 2014 to have the numerical example analysis which designed to achieve the system's key indicator early warning function; ultimately realize the equilibrium optimization of key indicators and business detail indicators and achieve the online and dynamic early-warning function of power grid enterprises' main business core indicators and key resources $^{[3]}$.

\section{Power grid enterprises' operation management early-warning model----SD model}

\subsection{Model Structure Design}

Model structure design is divided into three stages: Firstly, consult the indicator manual of power grid enterprise's operation monitoring business, sum up the key indicators which affect power grid enterprises' business operation mostly ${ }^{[4-6]}$, and decompose them into specific business department's business indicators; secondly, choose three business indicators as the key research objects which support the value dimensions, simulate the specific business process ${ }^{[7-10]}$, and connect the three business indicators with the specific business process; finally, make full use of Vensim which is a system dynamic analysis software to draw the system flow chart based on the key indicators of the corresponding business department ${ }^{[11]}$.

(1) Driving relation decomposition of value dimension key indicators

Total profit and return on net assets are both important indicators to evaluate profitability of enterprises and examine enterprise legal person. Decompose the driving relationship of these indicators.

(2) Driving relationship building of engineering construction business

Driving relationship of engineering construction business is with reference to the whole project process monitoring business thoughts from power grid operation monitoring (control) center. It is shown in Fig.1.

(3) Driving relationship building of operation and maintenance business

Driving relationship of operation and maintenance business takes the maintenance plan as a starting point, makes eliminate quantity and maintenance cost budget of abnormal device in maintenance plan as inputs, and then respectively forms device state evaluation indexes (transmission line/transformer normal state ration, transmission line/transformer note state ratio, 


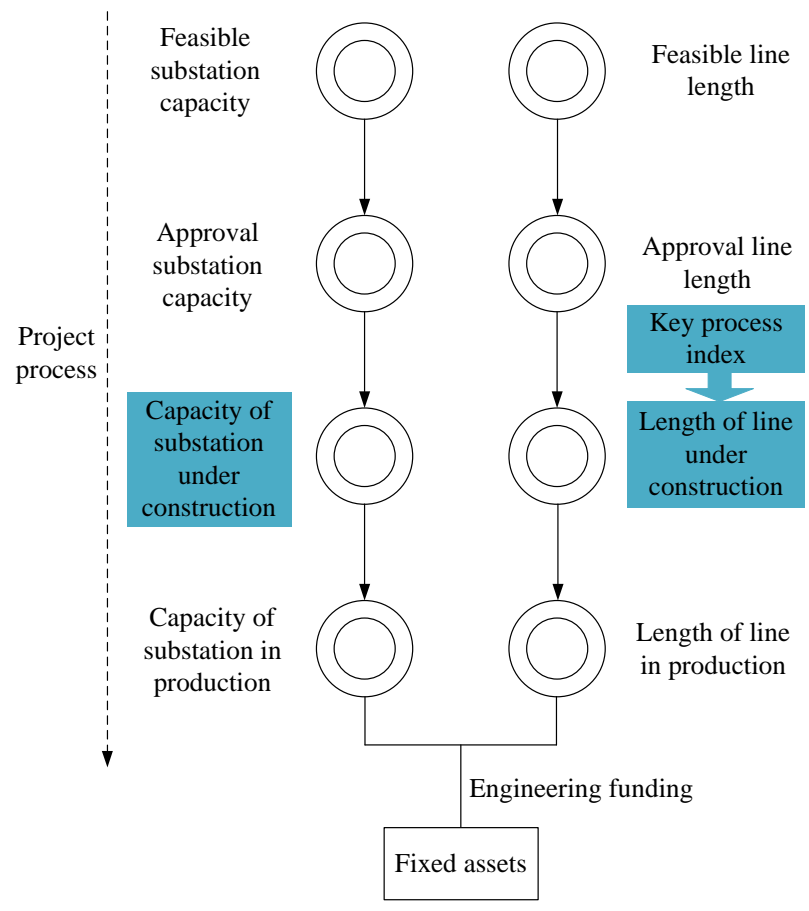

Figure 1. Project construction business module driver

transmission line/transformer abnormal state ratio, transmission line/transformer critical state ratio) and transmission and distribution cost index. It is shown in Fig.2.

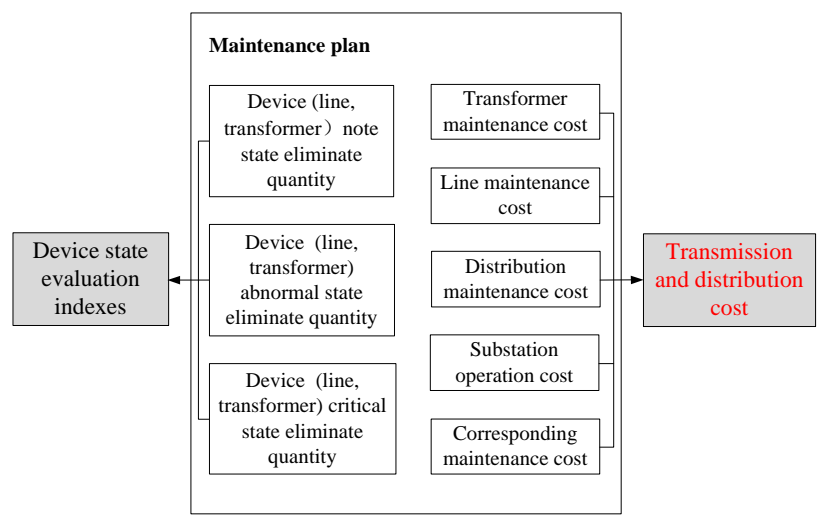

Figure 2. Operation maintenance business module driver

Device status evaluation is the work content of assets life cycle management. Currently, the evaluation of $220 \mathrm{kV}$ and above power grid device covers a total of about 20 types of device, and power grid operation and maintenance by means of making monthly maintenance plan to gradually eliminate non-normal state device, and then change the transmission line / transformer normal state ratio and other power grid operation and monitoring core indicators; the corresponding power grid maintenance costs budget can reflect the costs level of monthly power grid maintenance plan, and then realize the balance between performance and cost control.

(4) Driving relationship building of marketing expansion

Driving relationship building of marketing expansion business is based on the marketing department's electricity sales forecasting, and takes electricity sales forecasting data which based on the capacity utilization hours as input, then forms the driving relation of business expansion plans and capacity utilization hours to electricity sales. Consuming capacity can be divided into stock capacity and marketing expansion capacity, and stock capacity constitutes the basis of electricity sales market, while marketing expansion capacity is the main growing source of electricity demand. Marketing expansion business is starting from electricity consumption origins, and based on the capacity utilization and marketing expansion features of different customers to achieve the forecasting of electricity sales.

\section{Case study}

This article takes one provincial company as the analysis object, and uses the company's operating data for case study.

Key indicator early-warning shows the status of key indicators which need to be concerned by the decisionmakers of power grid operation and management, and provides an intuitive display and decision-making basis for indicator dynamic management and pre-control.

Put business indicators' actual and predicted values into the system dynamics model, and through simulation and calculation to obtain the trends of key indicators. As shown in the following diagram:

Using the company's historical data from January 2013 to March 2014 for calculation and simulation, and then obtain the forecast result in April 2014:

Among them, take the business indicators of planned budget and forecast data from May to August 2014 as input, and then obtain the results of it shown below in Fig.3.

By comparison indicators' actual values with the forecast values, it can be seen that the model can simulate the calculation structure of key indicators very well, and prediction results is accurate to some extent.

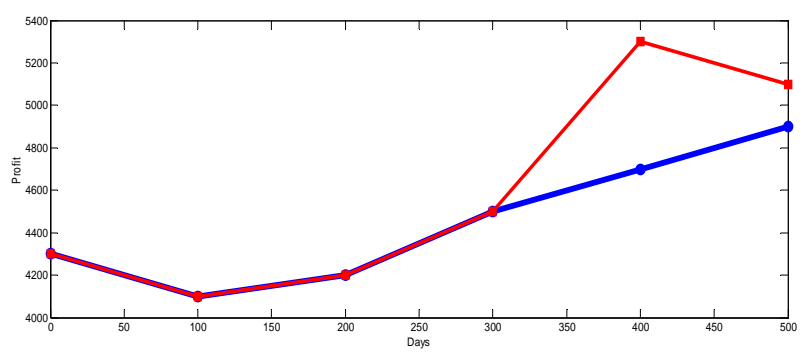

(a) Profit

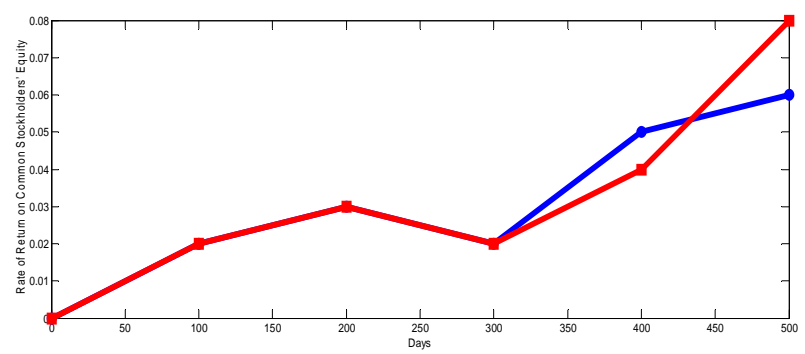

(b) Rate of Return on Common Stockholders' Equity 


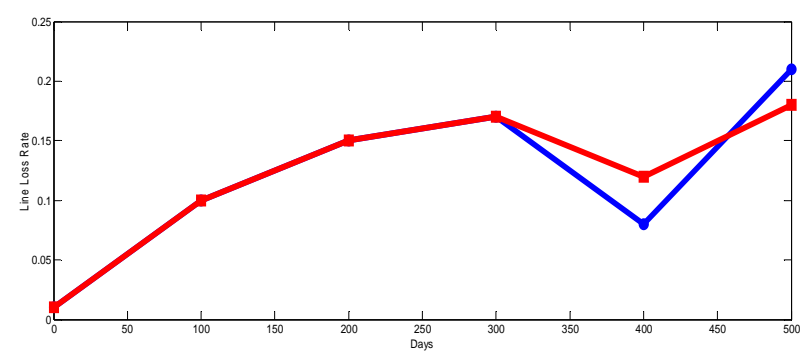

(c) Line Loss Rate

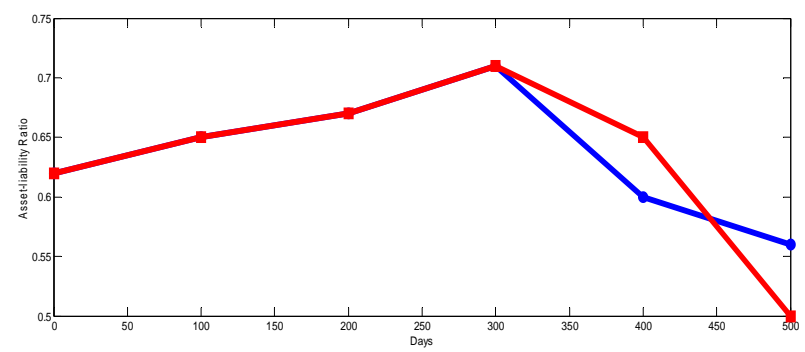

(d) Asset-liability Ratio

Figure 3. Key indicators development trend of 2014/04

By setting reasonable early-warning threshold to obtain the early-warning situation of key indicators in April 2014 are as follows in Fig.4:

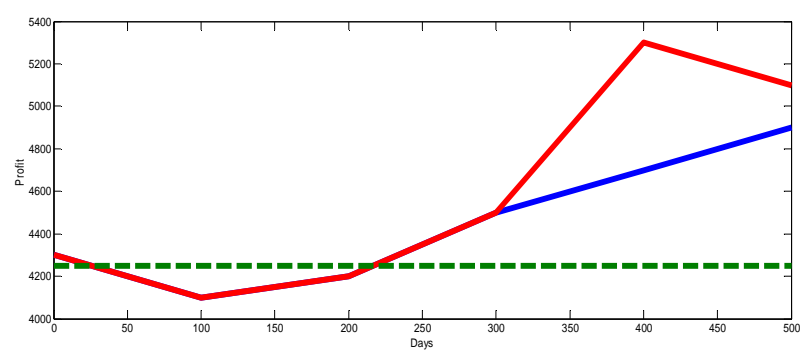

(a)Profit

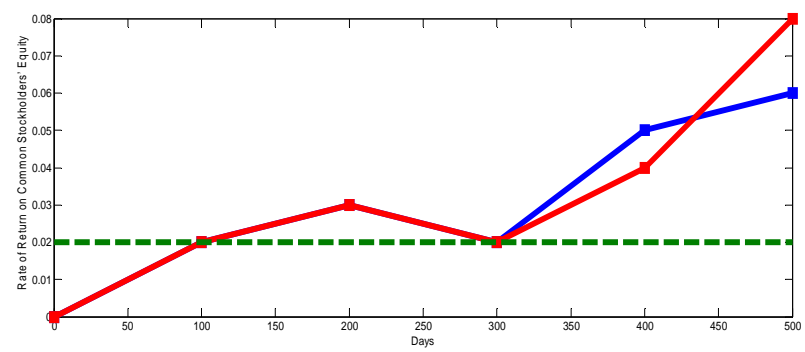

(b) Rate of Return on Common Stockholders’ Equity

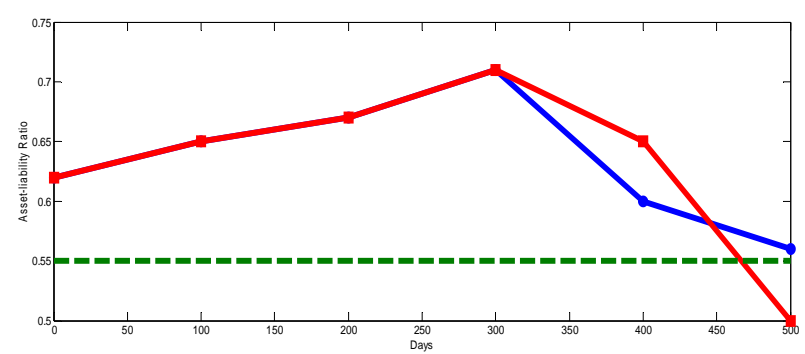

(c) Asset-liability Ratio

Fig. 4 Forewarning result of 2014/04

From the forecast results, it can be seen that the indicator values will below the lower early-warning threshold and by the analysis of operation and monitoring center, this is caused mainly by the increase in cost budget and link decrease ratio in expected electricity sales.

From January to March 2014, early-warning is normal, and we forecast the value of return on net assets will below the early-warning threshold after May which is mainly influenced by profits.

Implementation of asset-liability ratio is better, and it fluctuates within the early-warning thresholds.

\section{Conclusions}

In this paper, we take advantages of system dynamics theory in order to construct early-warning model for power grid operation and innovatively combine system engineering with power grid enterprises operation and management to provide theoretical support for power grid enterprises online operation early-warning. Meanwhile, in this paper we put to use one provincial power network enterprises' data from 2013 to 2014 for case study in data of analysis section, and apply the research results to one power grid enterprise's operation and management. By means of early-warning, we can receive the large number of early-warning status for return on net assets. And then operation and monitoring center sends early-warning signals to business departments which focus on the management and control of power purchase to satisfy the requirements of return on net assets annual plan.

The results show that the power grid enterprise earlywarning theory created in this paper can effectively improve some business function performances of power gird enterprises and strengthen the "early-warning machine" effect of operation monitoring center. And it makes contributions to power grid operation and realizes the coordinated development of value, development, efficiency and behaviors. Meanwhile, it not only improves the overall performance of power grid enterprises, but also plays a fundamental role of the decision-making optimization and operation support in social and economic development.

\section{References}

[1] Xiaoli Zhao, Thomas P. Lyon, Cui Song. Lurching towards markets for power: China's electricity policy 1985-2007. Applied Energy; 94:148-155 (2012)

[2] F.R. Pazheri, M.F. Othman, N.H. Malik. A review on global renewable electricity scenario. Renewable and Sustainable Energy Reviews;31:835-845 (2014)

[3] Huanan Li, Hailin Mu, Shusen Gui et al. Scenario analysis for optimal allocation of China's electricity production system. Sustainable Cities and Society;10:241-244 (2014)

[4] Zeng Ming, Ouyang Shaojie, Zhang Yingjie, Shi Hui. CCS technology development in China: Status, problems and countermeasures-Based on SWOT analysis. Renewable and Sustainable Energy Reviews;39:604-616 (2014)

[5] Bo Zeng, Ming Zeng, Song Xue, Min Cheng, Yuejin Wang, Junjie Feng. Overall review of wind power development in Inner Mongolia: Status quo, barriers 
and solutions. Renewable and Sustainable Energy Reviews;29:614-624 (2014)

[6] Karen Fisher-Vanden, Erin T. Mansur, Qiong (Juliana) Wang. Electricity shortages and firm productivity: Evidence from China's industrial firms . Journal of Development Economics;114:172-188 (2015)

[7] Wang Qiang, Chen Xi. China's electricity marketoriented reform: From an absolute to a relative monopoly. Energy Policy;51:143-148. (2012)

[8] $\mathrm{Ke} \mathrm{Li}$, Boqiang Lin. The efficiency improvement potential for coal, oil and electricity in China's manufacturing sectors. Energy;86:403-413 (2015)

[9] Fei Teng, Xin Wang, LV Zhiqiang. Introducing the emissions trading system to China's electricity sector: Challenges and opportunities. Energy Policy;75:3945 (2014)

[10]M.K. Barai and B.B. Saha. Energy security and sustainability in Japan. EVERGREEN Joint Journal of Novel Carbon Resource Sciences \& Green Asia Strategy ,2(1):49-56 (2015)

[11] Y.S. Cheng, W.K. Wong, C.K. Woo. How much have electricity shortages hampered China's GDP growth?. Energy Policy;55:369-373 (2013) 